\title{
Using Audio-Visual Aids and Computer-Assisted Language Instruction (CALI) to Overcome Learning Difficulties of Speaking in Students of Special Needs
}

\author{
Sadeq Ali Saad Al- Yaari (Corresponding author) \\ Independent Researcher, Dept. of English, College of Arts, King Saud University (KSU) \\ Riyadh, Kingdom of Saudi Arabia \\ E-mail: prof.sadeq@gmail.com
}

Received: October 28, 2013 Accepted: November 10, 2013 Published: December 12, 2013

doi:10.5296/jsel.v1i2.4743 URL: http://dx.doi.org/10.5296/jsel.v1i2.4743

\begin{abstract}
Background \& Aims: Teaching speaking skill has always been a part of teaching any language skills as it helps language learners to promote self-presentation. It is known that speaking is a result of listening. Here, we asked if using audio-visual aids and computer-assisted language instruction (CALI) by speech language Therapists (SLTs) could make differences in the performance of the students of special needs.

Methods: The performance of forty students (males and females) of special needs between 818 years old study speaking at al-Malādh school for teaching students of special needs was compared that of another group (control group) of the same number and similar age. Both groups underwent the treatment by the same SLT except for that with the first group, the SLT used audio-visual aids and CALI but not with the other. Pre-and-posttests have been administered at the beginning and end of the semester (Before and after teaching speaking course). Students' performance was linguistically and statistically assessed.

Results: Outlined results revealed a greater pattern of differences between the two groups and this can be clearly seen in the performance of the first group (where audio-visual aids and CALI were used) at the posttest $(74.07 \%$ vs. $25.52 \%)$. In comparison to the males' performance level, the females registered higher scores than those scored by males (1494 vs. 1469). When optimized, these data partially support the idea that using audio-visual aids and CALI are important in teaching language productive skills in general and speaking skill in particular.
\end{abstract}

Keywords: Speaking, productive skills, students, Special Needs, Audio-Visual Aids, CALI 


\section{Introduction Chapter}

\subsection{Introduction}

Audio-visual aids and CALI are associated with the improvement of language skills be it receptive skills or productive skills or even language components (Gilakjani, 2012). These educational aids are found to be useful not only for normal students, but also for students with special needs (Iram, 2012; Kirk, et al., 2012). Explaining the reasons behind the new trend, Kirk and his colleagues have rightly observed: "Such tests, in which acoustic variability is highly constrained, may not accurately reflect spoken word recognition abilities under more natural listening situations." (Kirk, et al., 2012: p. 455)

To study how audio-visual aids and CALI affect the ability of the normal students and those of special needs, improve their productive skills, some researchers went further to investigate the process of recognizing the word in the brain before it is articulated. According to them, articulation is the ice-berg of the pronunciation process which is preceded by brain process Bradham (2012). The operation takes place, according to Bradham when "Outer hair cells provide mechanical feedback into the organ of Corti, thus enhancing the input to the inner hair cells, which predominantly send information to the central nervous system." (Bradham, 2012: Abstract)

Such findings inspired researchers to ask legitimate and reasonable questions relating to the ways information are processed in the brain and the relationship between motion representation and the visual motion system (Pavan \& Baggio, 2013). More importantly, how and where does this process take place in the brains of students with special needs, especially when it comes to matters relating to deep/ surface reading for example (Wolf, et al., 2012) or those concerning Braille-reading and the way to understand issues like shape and space by blind students (Klingenberg, 2012). Onnis \& Thiessen (2013)'s findings suggest that mechanisms of statistical sequential learning are implicated in language across the lifespan, and experience with language may affect cognitive processes and later learning.

Others went further by investigating not only the patients, but also the role of the parents and other people around the child which results "in greater exposure to the majority language. (MacLeod, et al., 2013) :p. 132). New trends of the research in this field started to focus on physicians and nurses and the way they read, write, etc. (Khaliq, et al., 2012; Peinhardt \& Hagler, 2012).

Furthermore, scientists established a new trend whereby language aspects could be linked together. The study of Diaz-Maurin \& Giampietro (2013) investigated the impact of grammar for assessing the performance of power-supply systems. Having the nuclear energy and fossil energy compared to each other, the researchers concluded that when considering internal constraints, nuclear energy requires about twice as much power capacity and 5-8 times more labor. Diaz-Maurin and his colleague confirmed that things do not improve for nuclear energy when looking at external constraints which may explain the difficulties faced by nuclear energy to gain interest from investors.

Despite of the fact that audio-visual aids and CALI made better progress in the levels of 
students, some researchers are still believe in the original methods as effective means through which students can acquire language skills, notably reading, listening and writing (Devimeenakshi \& Maheswari, 2012). Additionally, pedagogical-based aids were present with more theoretical views but not with more practical use. Consistent with the existing literature on other audio-visual aids and CALI, at least film is common in the field of education (Swimelar, 2013). Knowing the prevalence of boards, notably for teaching students of special needs supplements educational interpretation and can overcome the learning difficulties they suffer from? Many studies have been conducted in this field like Gessesse \& Sileshi (2013)'s study whose purpose was to examine visual semiotic signs and bill-boards and their communication implications, especially if they are used for patients. It appears to in favor of this that Gessesse and her friend have forwarded the following notification: "all the visual semiotic signs on all these billboards would give a much wider picture of the types and applications of visual semiotic signs. For another, it would also provide greater opportunities to identify the genres of messages represented through these visuals semiotic signs" (Gessesse \& Sileshi, 2013: p. 246)

Students of special needs frequently encounter learning difficulties related to audio, visual or audio-visual texts. Some difficulties can be subtle but can seriously influence the students' ability to learn. The article of Brown et al., (2013) proposes that differing types of annotation cf-141293233 offer a powerful and flexible technique for transferring the benefits of graph-based diagrams, as well as for reducing disorientation while moving around the graph and for tackling some of the inherent disadvantages of using sound. According to Brown and his friends, graph annotation may be performed automatically, creating a graph that evaluation shows requires less mental effort to explore and on which tasks can be achieved more effectively and more efficiently. Such results received high support from Chen \& Yen (2013) who concluded their study by providing insights on the design and instruction, not only for written text reading, but also for online reading.

The technological features of reading software that can be used for word recognition have not been explicitly investigated, but they may not be comparable because some techniques do not follow the same distinctive features and other qualities of others. The study of Damoiseaux, et al., (2012) may be a valuable source of information for refining our understanding of some of this software in general. Damoiseaux and his friends discussed the automatic reading of anti-neutrophil cytoplasmic autoantibody (ANCA-Slides). The purpose of the research team was to evaluate the AKLIDES System. The team emphasize that the results are promising in that the pattern recognition may play an important role in ANCA-associated vasculitis diagnostics.

Some researchers investigated the idea of how blogs could be used for language purposes. The article of Álvarez (2012), for example, presents a study on the best ways of using blogs as a tool to improve students' reading and writing skills. The results showed that blogs are reliable tools for the improving students' productive skills. A total of 186 English as second language (ESL) elementary school subjects underwent the study of Ismail, et al, (2012). The aim of the study was to dis/prove whether or not using technology helps ESL learners improve their reading and writing skills. There are significant differences in the performances 
of the ESL students. This can be obviously seen in the outcomes of the qualitative and quantitative analyses of the scores. According to Ismaeil and his team, technology might play crucial role in assisting students to learn reading and writing skills. Other significant results, the researchers added, revealed that technology helped teachers in assigning extracurricular activities and communicating with students.

There has been growing interest recently in the use of multimedia as audio-visual aids to decode information and facilitate messages from high-dimensional scientific facts and present them to English as foreign language (EFL) students. The study of Fuenzalida \& Sjöberg (2012) employed a support vector machine-based T.V approach to teach EFL students language skills, especially for young learners. Such results were supported by the study of Ahmed (2012). Gower \& McDowall (2012) assessed the role of interactive video games on educating children during the study of language skills and/ or language components. Eleven subjects ( 9 children and 2 music specialists) underwent the experiment. The two researchers concluded their study by recommending the use of audio-visual aids and computer-assisted/ aided language instruction (CALI) as useful educative means when they are used for teaching EFL students.

In their study, Anson \& Schwegler (2012) aimed at investigating tracking mind's eye technique. Anson and his colleague wanted to examine the usefulness of this strategy to be implemented for improving foreign language students' reading skill. Nevertheless, the study also highlighted the need for further research into how to improve such technique in composition studies, especially at the intersection of writing. Although currently only a few randomized controlled studies investigated the efficacy of tracking the movement of the eye, such outcomes received a great support by many researchers in the field who conducted similar studies. (Henderson \& Luke, 2012; Perea, 2012)

Audio-visual aids and CALI had a strong internal and external consistency on the performance of the students. The test-retest and intra- and inter-rater reliabilities were shown to be adequate when it comes to talk about the effectiveness of the audio-visual aids and CALI, and the same thing applies to discriminant validity which was good in most of the conducted studies. For new techniques related to audio-visual aids and CALI, different outcomes were found: apart from one correlation, the scores on tests assessing a language skill and/ or a language component correlated significantly with outcome measures of similar methods. One of those methods is graphic organizer method designed by Manoli \& Papadopoulou in 2012. According to the researchers, the study constitutes an attempt to shed light on the research evidence regarding the effectiveness of graphic organizer on text learning and the various types of graphic organizers, which use different conventions to communicate information and are classified in various ways. The researchers finished their study by recommending ways of integrating them in reading lessons, touches on the issue of strategy instruction and its effects on language learning and leaves room for further exploration.

Mengoni, et al., (2013) tested the benefit of orthographic support for oral vocabulary learning in children with Down syndrome. There were 17 students of special needs over 6 years of age, 
with Down syndrome, in the developing phase and 27 typically developing children aged 5 to 7 years matched for reading ability. . The main outcome measures were weighted on the ten spoken non-words that were paired with novel pictures and significance levels of differences between the groups of subjects who were expected to differ in terms of scores, on the basis of the instruments used in the assessment process. The results were as follows: Children with Down syndrome are not specifically impaired in phonological learning and benefit equally from orthographic support.

Sigrist, et al., (2013) addressed the importance of technical display as means through which motor learning is enhanced, recommending using these audio-visual aids in addition to CALI. According to the research team, such audio-visual aids and CALI are important means that should be extensively used for teaching language skills due to their usefulness that can be clearly seen in the EFL students' multimodal feedback. Rahimy \& Asaei (2012) investigated the ability of the Iranian EFL students to speak in light of a new treatment. The aim of the study was to explore skill-related changes in functional audio-visual aids and CALI efficiency in teaching. Sixty junior subjects were randomly selected and included in the study, matched for age, and education level. They were divided into two groups $(30 \times 30)$. Both groups underwent intensive 10 sessions where the former group (treatment group) received the treatment (studying productive skills using audio-visual aids and CALI, the other group (control group) did not. Results demonstrated that the control group showed worse performance on the posttest in comparison to the control group. The researchers could not ignore the importance of listening where they admit: "Oral proficiency (Speaking) has been strongly affected by the listening comprehension skill." (Rahimy \& Asaei, 2012: p. 609)

These results, according to the researchers, underline the importance of implementing audio-visual aids and CALI in teaching productive skills, notably speaking skill to EFL students. Using word identification fluency to monitor first-grade reading development is an experimental study conducted by Zumeta, et al., in 2012. The aim of the study of Zumeta and his colleagues was to describe the phenomenon under investigation by assessing the effects of sampling breadth on technical features of word identification fluency. The researchers described the most influenced effects, and distinctive features of the new technique. To that end, a total of 704 first-grade students participated in the study. Data collection, according to the research team, continued weekly on broadly and narrowly sampled word identification fluency lists for 15 weeks. The overall outcomes demonstrate the validity and utility of the method as a supplement to speech tasks in assessing students' performance. In particular, the findings revealed that narrow sampling was better for screening the representative group and the high/average subgroup. Broad sampling was superior for screening the low-achieving subgroup and for progress monitoring across groups. The impression is made that, for the future experimental studies, it is needed to integrate comprehensive knowledge, derived from similar studies, testing researches and improvement of conceptual-production systems models, movement researches in functional, practical and social context.

\subsection{Aims of the Study}

This study attempted to test the main and interaction effects of using audio-visual aids and 
CALI in the performance of students of special needs in speaking skill. To this end, the researcher aims to find answers for the following questions:

1. What are the audio-visual aids and CALI that can be used for teaching students of special needs language in general and speaking in particular? To what extent can SLTs benefit from them when teaching this class of students? What are the best methods that can be effectively used for implementing these educative aids in a way that guarantee improving students of special needs' performances.

2. Compared with those who do not use them, do audio-visual aids and CALI make any difference when they are used for teaching speaking skill to students of special needs? Are there any results of other studies that agree or contradict the findings of the present study?

\subsection{Methodology}

Eighty students of special needs (age ranges between 8-18 years old) of both sexes were enrolled in this experimental study. The subjects were randomly divided into two groups; each group consists of 40 students. Nearly all students suffer different types of aphasias. They underwent a course on speaking skill, for a semester (4 months) at al-Malādh school for teaching students of special needs in Dhamar city, republic of Yemen. The purpose of the study was to examine the effectiveness of audio-visual aids and CALI when they are used for teaching productive skills in general and speaking skill in particular. Before and immediately after the first speaking lesson, the subjects under investigation performed a pre-test and at the end of the semester, another post-test was administered to them by their SLT who was teaching the two groups at the same school. In between the treatment, the first group studied using audio-visual aids, while the second group studied using ordinary methods (chalk and black boards). Outcomes of the two tests were linguistically and statistically assessed. In this regard, social program for social sciences (SPSS) was implemented to describe the frequencies.

\section{Analysis}

2.1 Using audio-visual aids and CALI to teach students of special needs language skills in general and speaking skill in particular

Educative aids are frequently used in language practice to help students learn very well. Recently, psychoneurolinguists and speech language therapists (SLTs) have realized that using these aids is of special importance to students of speech needs. According to experts in the field, these educative aids are found to be useful for those students who are suffering from adidadochocinesia, anarthria, visual agnosia, and color blindness (e.g., deuteranomalopia, anianthinopsy, etc.). These divided the practical part of these educational aids into two broad categories:

1. Conventional aids.

2. Computer learning in language teaching.

A very legitimate question that poses itself in this regard is the following: 
Why do we use aids in language teaching in general and what are the benefits of using them for students of special needs? To answer such reasonable questions, one needs to understand that aids can be used for many language purposes. Some of these purposes can be listed as follows:

- Attracting attention.

- Maintaining attention.

- Clarifying concepts and meanings of words and utterances.

- Increasing chances of remembrance.

- Time saving (1 picture is worth 1000 words).

- $\quad$ Adding varieties to class activities.

- Compensation for the lack of experience in teachers (e.g., bringing pictures for throat to compensate for his inability to draw).

- Individualizing learning and teaching (e.g., giving students cassettes to be listened to at home or program instruction which takes forms like the book, for example, which is the simplest form and which contains some forms that have some bits of information and each bit of information has its feedback in the margins, etc.

- Involving learners: Either by asking them to participate in class activities or by using pattern practice which can be done by computer recording. Consider:

- John is reading a book.

- $\quad$ Mary.....................

(Instant feedback varies according to the situation e.g., I'm sorry, good answer, well done, excellent, try again, etc.).

- Presenting authentic language e.g., listening to a native speaker, giving menus to the students, recordings of airport's announcements, news, etc.

- Simulation of language use (e.g., acting, dramatization, etc.).

Clearly, educational aids can be used for different purposes. We can use them for teaching language skills and language components. In detail, educational aids can be used for teaching oral skills (listening and speaking) and written skills (reading and writing) and components of language (sound system, grammatical structures and vocabulary building). Educational aids for teaching language skills and language components fall into five major types: Visual aids, audio aids, audio-visual aids, action (e.g., dramatization, field trips, debating, etc.), and multi-media (Computer-assisted language learning/ instruction/ teaching (CALL/I/T)).

A: Visual aids: This type takes different forms and shapes:

○ Realia (Real things). This includes chalk, board, chair, etc. 
○ Three dimensions models (e.g., trains).

○ Pictures or drawings: These can be photographic or hand drawn. There are different types of pictures:

- Simple pictures: Pictures of cars, pens, books, etc.

- Composite pictures: Pictures of scenes in classes, movies, etc.

- Series or sets: For example, telling stories, process of doing something (cooking, manufacturing, experiment, etc.), pictures of transportation means, etc.

○ Posters: Usually consists of picture and text (e.g., posters of "No Smoking").

- Maps: These include geographical maps (used for topographical purposes), political maps, city plans, floor plans, etc. SLT can use city plan for example and ask the student who suffers from dyslexia to follow his instructions by drawing lines on the places he/ she is talking about.

○ Boards: There are many of them like smart boards, white boards, black boards, etc.

- Cards: These include flash cards (where the picture is in one side and the word is in the other side), reading cards, and question \& answer cards, etc.

- Graphs: One of the most famous graphs is the pie graphs. Pie graphs are normally used for statistical purposes.

○ Forms: To be used by students who are suffering from dysgraphia for example. Examples of forms: Immigration forms, customs forms, hotel forms, etc.

- Menus: Restaurant menus that can be used to teach mentally handicapped students something about cultures, traditions, folklores, etc.

- Slides: Overhead projectors (OHP) slides and $35 \mathrm{~mm}$ slides are some of the example for this type of visual aids. Many of the above mentioned visual aids can be converted into slide forms and then presented to the students of special needs to achieve some class activities.

- Film strips: It is a set of slides like picture series. SLTs can also make use of silent films.

- Comic books: Examples of this type are children books, stories, etc. that can be used to entertain children, notably those who have problems relating to dyscalculia. Such type also attracts the attention of students suffering from dysarthria and prompts them to speak.

- Facial diagrams: Diagrams to be taken from books like phonological books or even by drawing them on the boards for teaching purposes like teaching articulation for those who are suffering from pronunciation problems.

- Clock, face, and hands: By asking the students to assign the time according to the question or vice versa. Such types of activities help dyscalculic students learn better.

- Calendars: For counting days of the week, months of the year, numbers, etc. Again, such drill gelps those who suffer from dyscalculia. 
- Letters of the alphabet and numbers: For teaching spelling, recognition of the letter, etc.

○ Cross-word puzzle: For teaching vocabularies. We also have scrabbles. Learning vocabulary items is very helpful for those who have developmental aphasia.

○ Tables \& schedules: These include time table, flight schedules, tec. Linking information to each other helps those who have global aphasia as it strengthens their abilities to speak and comprehend.

B: Audio-aids: Some audio aids that can be used for students who have language difficulties are:

- Cassette recorder or radio: Such audio aid is typical, notably for those who have problems related to Wernicke's aphasia as it helps them comprehend what they are listening to. Those who suffer from conduction aphasia may benefit from these cassettes also as they have to repeat the words and / or phrases they are listening to. In others, they do not have to listen to themselves and repeat their own sentences more than one time.

- Phonograph records: It is an old version of compact discs (CDs).

- CDs.

- Conversional language labs: In this kind of labs, one can have all the above mentioned audio aids.

C: Audio-visual aids: The most obvious types are T.V, videos, and also digital versatile disc (DVD) which has almost the same function as the video tape. Sophisticated language lab is another audio-visual aid. In this kind of labs, students of special needs can have both recording and playing. They can also have the facility to speak and listen at the same time and then compare that. Another characteristic of these labs is the facility of instant repetition. Sound movies are also some other types of audio-visual aids. These movies are now replaced by video tapes. Sound movies are the opposite of silent movies. SLTs can mute the sounds so that movies can be functioned for speaking or with the sound for listening. Slide/ sound synchronization is another type of audio-visual aids. In this type, students of special needs can have both sound and picture and this is used to be one of the methods used in the past and is called in French "La method audio-visuelle".

D: Action: This takes different shapes and forms:

冈 Dramatization (physical action) like walking, standing up, etc. Such exercises are helpful for students suffering from Alalia. However, if the SLTs notices that his/ her student cannot act the action, then they can ask them (using sign language when necessary) to pantomime or imitate.

冈 Charade: Charade is a good exercise due to those students of special needs enjoy it so much. In this type of exercises, SLTs are supposed to play a role of something and their students predict what it is. 
冈arty games: Many of them can be used be used as means for teaching language skills in general.

$\otimes \quad$ Language teaching games: They can be found in magazines, etc.

Field trips: They teach students of special needs some vocabularies. Students of special needs can also get practical experiences with them.

$\bigotimes$ Role playing: It is a good example of actions.

冈 Physical response: It is considered one of the ways of performing actions.

E: Multi-media aids (CALL/ CALT): They are combination of all the above mentioned aids including the use of internet, etc. Nor must we forget some general programs like T.V, radio, etc. SLTs should also pay attention to the use of computer as only one aspect of aids in language learning. It is important, however, that SLTs know the best ways to use the above mentioned educative aids in teaching language to their students of special needs. Based upon what has been mentioned above, it can be said that such educational aids are important for students who are suffering from language difficulties in general and laryngopharyngitis, laryngophthisis, laryngoplegia, laryngoptosis, and laryngotracheitis. Some requirements for proper use of these educational aids (selection \& use) are as follows:

$\checkmark$ Aim (objective): In this regard, SLT should ask himself/ herself "Why am I using this aid in particular (a picture for instance)? Why not another/ other aid(s)?"

$\checkmark$ Effectiveness: Again, SLTs should ask themselves questions regarding to the effects (positive, negative, or side effects). Examples of these questions are: How effective is the use of this educative aid? What shall I do to make that educational aid more effective bearing in mind time, environment, students' levels, individual differences, types of language disorders, etc. For example, a documentary art subject will help students with dysmnesia remember things: Should I use it as a whole or just segment it in sections? When shall I use it? Shall I use it at the beginning, in the middle or at the end of the class?

$\checkmark$ Resources: Questions relating to the availability of the educational aids. These include: Where can I get the educative aid (s)? Are they available in toys' stores, bookstores, or internet?

$\checkmark$ Preparation: Making sure whether this educational aid is useable or not (usability of the educative aids and the best way (s) to use it.

Let's take an example of using these educational aids for teaching speaking skill, but before that, SLTs should know that speaking falls into two types: Monologue (It occurs when the person talks to himself) and conversation (It occurs between two persons or more). Some requirements for teaching speaking skill can be explained as follows:

Recognition/ production of sound system.

Grammatical structures, lexical items, functions, etc. 
Discourse markers (Connecting sentences together), translation, expressions like moreover, however, forever, the like, so forth, in conclusion, in summary, furthermore, etc.

* Paralinguistic signals/ features including facial expressions, gestures, body actions, mimes, etc.

\# Rules of interaction (how to begin, end, and interrupt a conversation).

Technically, speaking, as is mentioned earlier, refers to a monologue (a person's own speech), a conversation (between two and/ or more), a dialogue or a chorus. Unlike monologue where there is no interaction between listening and speaking, in conversation, dialogue, and chorus, there is. In fact, conversation has something to do with issues related to discourse rules, especially when talk about culture like recognizing others' term taking rules of culture. SLTs should realize an important fact that is from among the two productive skills (speaking and writing), speaking is usually if not always, introduced first. This is because writing requires discussion which, in turn, requires speech (speaking). Now, the question that SLT should ask is the following: What educative aid (s) should I use for teaching speaking skill? Before answering this question, SLTs need to know that one of the problems that he/ she faces in teaching speaking skill is that he/ she (SLT) needs to provide the students of special needs with ideas; therefore, a number of audio-visual aids and CALI can help him/ her do this.

Among these audio-visual aids and CALI that can be used for teaching speaking skill to students of special needs is the picture (according to the situation). For example, simple pictures can be used for teaching simple utterances, composite pictures can also be used for teaching dialogues and the sets of pictures can be implemented for teaching stories). Maps, floor plans, street maps, etc. can be used for descriptions. Drawings can be implemented to express the process of doing something like food preparation. Graphs can be statistically presented by researchers for statistical purposes. All the above mentioned audio-visual aids and CALI provide the students of special needs with the ideas that will, surely, help them speak and overcome their learning difficulties in speaking skill.

Alternatively, SLTs can make use of audio-texts where students of special needs can listen, repeat and practice what they have already listened to. Written texts can also be implemented here. Students of special needs are asked to read the text and then summarize orally what they have read which means that they practice speaking skill. Additionally, interviews -based on application forms- can be used too. One more audio-visual aid but rarely used for speaking skill (mostly for writing skill) is combination-tables, where a student selects words from the table and form a sentence (utterance) to say it orally and the same thing applies to the use of cards (words).

An important common audio-visual aid that can be used for teaching speaking skill is the role play (usually called action aid) where students of special needs act and play roles to converse with each other. SLTs can also use prompt words. They are words refer to particular topics (key words) to help students of special needs speak. Watching programs is a very important educative aid where the SLT puts the volume in mute and then ask the students of special needs to speak on behalf of the actors. Also, he/ she can ask them to summarize report and/ or 
comment what they have already watched which means, again, that the students of special needs practice the speaking skill. Language labs are also important educational aids where students practice and repeat. Tape recording is also of special importance where students of special needs can listen, tape themselves and then compare and evaluate themselves along with their SLT. Computers (speaking software/ simulations for interaction), internet for oral communication (Skype, Hotmail, yahoo, maktoob, gmail, mail, etc.) are also important audio-visual aids that cannot be neglected. Looking at it from a psychoneurolinguistic viewpoint, all the above mentioned audio-visual aids and CALI can be used for teaching speaking skill students of special needs in general and those who are suffering from anarthia, prosopagnosia, dysphonia, etc.

\subsection{Audio-visual aids and CALI: Effects in the performance of students of special needs}

Psychoneurolinguistically, this study investigated correspondence between different measures of speaking skill. Forty subjects (Experimental group) and 40 subjects (Control group) were given pre-and-posttests. The aim of administering these tests is to present normative data for the usability of audio-visual aids and CALI to increase the ability of the students of special needs to speak and articulate sounds properly. In order to do that, the following pre-test was administered to both treatment group and control group. In Table 1 below, the normative data obtained will be useful in the overall evaluation of the posttest for comparative purposes. Consider:

Table 1. Performance of the subjects in the pre-test: Comparison between the treatment and control groups

\begin{tabular}{|c|c|c|c|c|c|c|c|c|}
\hline \multirow[b]{2}{*}{ No } & \multicolumn{4}{|c|}{ Treatment/ Experimental group } & \multicolumn{4}{|c|}{ Control group } \\
\hline & Subject Name & 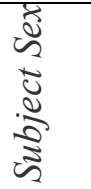 & 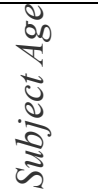 & $\begin{array}{l}50 \\
\overline{0} \\
5 \\
5 \\
5 \\
5 \\
5\end{array}$ & $\begin{array}{r}\text { Subject } \\
\text { Name }\end{array}$ & 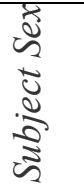 & 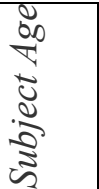 & 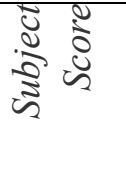 \\
\hline 1 & Saleh & M & 18 & 23 & Nada & $\mathrm{F}$ & 15 & 37 \\
\hline 2 & Majed & $\mathrm{M}$ & 12 & 24 & Hajar & $\mathrm{F}$ & 14 & 9 \\
\hline 3 & Saqr & $\mathrm{M}$ & 14 & 38 & Hamas & $\mathrm{F}$ & 8 & 12 \\
\hline 4 & Ali & M & 8 & 18 & Rashad & M & 12 & 48 \\
\hline 5 & Amatallateef & $\mathrm{F}$ & 12 & 29 & Omar & M & 9 & 36 \\
\hline 6 & Amatala'leem & $\mathrm{F}$ & 9 & 38 & Ashraf & M & 16 & 41 \\
\hline 7 & Badr & $\mathrm{M}$ & 13 & 16 & Mohammad & $\mathrm{M}$ & 11 & 30 \\
\hline 8 & Tareq & M & 14 & 11 & Montaha & $\mathrm{F}$ & 14 & 38 \\
\hline 9 & Parees & $\mathrm{F}$ & 15 & 7 & Ayman & M & 13 & 28 \\
\hline 10 & Bayrout & $\mathrm{F}$ & 9 & 29 & Aayah & $\mathrm{F}$ & 10 & 17 \\
\hline 11 & Tammaah & $\mathrm{M}$ & 9 & 40 & Adham & $\mathrm{M}$ & 10 & 36 \\
\hline 12 & Taher & $\mathrm{M}$ & 17 & 24 & Nasser & M & 11 & 39 \\
\hline 13 & Baraah & $\mathrm{F}$ & 16 & 24 & Haylah & $\mathrm{F}$ & 17 & 20 \\
\hline 14 & Abrar & $\mathrm{F}$ & 11 & 16 & Tawfeeq & $\mathrm{M}$ & 13 & 25 \\
\hline 15 & Ahmad & M & 13 & 39 & Nour & $\mathrm{F}$ & 12 & 29 \\
\hline
\end{tabular}




\begin{tabular}{|r|r|r|r|r|r|r|r|r|}
\hline 16 & Fatimah & $\mathrm{F}$ & 16 & 35 & Najeebah & $\mathrm{F}$ & 18 & 28 \\
\hline 17 & Amatillah & $\mathrm{F}$ & 18 & 26 & Radha'a & $\mathrm{F}$ & 16 & 17 \\
\hline 18 & Abdullateef & $\mathrm{M}$ & 8 & 29 & Wafa'a & $\mathrm{F}$ & 15 & 13 \\
\hline 19 & Amriyah & $\mathrm{F}$ & 12 & 20 & Wajedah & $\mathrm{F}$ & 15 & 44 \\
\hline 20 & Abduljaleel & $\mathrm{M}$ & 12 & 33 & Sultan & $\mathrm{M}$ & 9 & 37 \\
\hline 21 & Kareemah & $\mathrm{F}$ & 11 & 28 & A'simah & $\mathrm{F}$ & 12 & 20 \\
\hline 22 & Nadiyah & $\mathrm{F}$ & 11 & 30 & Adalah & $\mathrm{F}$ & 11 & 29 \\
\hline 23 & Sariyah & $\mathrm{F}$ & 13 & 36 & Abulwali & $\mathrm{M}$ & 8 & 21 \\
\hline 24 & Sarah & $\mathrm{F}$ & 13 & 26 & A'amal & $\mathrm{F}$ & 8 & 18 \\
\hline 25 & Huda & $\mathrm{F}$ & 18 & 16 & Salah & $\mathrm{M}$ & 12 & 26 \\
\hline 26 & Sulayman & $\mathrm{M}$ & 15 & 19 & Ammar & $\mathrm{M}$ & 13 & 18 \\
\hline 27 & Amjad & $\mathrm{M}$ & 14 & 20 & Luluah & $\mathrm{F}$ & 18 & 8 \\
\hline 28 & Abdullah & $\mathrm{M}$ & 11 & 35 & Bilal & $\mathrm{M}$ & 14 & 12 \\
\hline 29 & Abdulmajeed & $\mathrm{M}$ & 16 & 40 & Ziad & $\mathrm{M}$ & 12 & 40 \\
\hline 30 & Raghad & $\mathrm{F}$ & 15 & 44 & Ruqayah & $\mathrm{F}$ & 18 & 19 \\
\hline 31 & Hafsah & $\mathrm{F}$ & 14 & 23 & Asma'a & $\mathrm{F}$ & 15 & 38 \\
\hline 32 & Abdurrahman & $\mathrm{M}$ & 14 & 32 & Sumayah & $\mathrm{F}$ & 17 & 48 \\
\hline 33 & Akram & $\mathrm{M}$ & 14 & 17 & Kawthar & $\mathrm{F}$ & 13 & 39 \\
\hline 34 & Taqwa & $\mathrm{F}$ & 13 & 27 & Khawlah & $\mathrm{F}$ & 14 & 29 \\
\hline 35 & Salma & $\mathrm{F}$ & 12 & 28 & Tasneem & $\mathrm{F}$ & 18 & 17 \\
\hline 36 & Hadiyah & $\mathrm{F}$ & 18 & 34 & Amal & $\mathrm{F}$ & 10 & 23 \\
\hline 37 & Sayda & $\mathrm{F}$ & 18 & 43 & Sami & $\mathrm{M}$ & 10 & 44 \\
\hline 38 & Abdulkareem & $\mathrm{M}$ & 16 & 28 & Haneen & $\mathrm{F}$ & 10 & 27 \\
\hline 39 & Sadeq & $\mathrm{M}$ & 8 & 27 & Ayham & $\mathrm{M}$ & 16 & 23 \\
\hline 40 & Motaz & $\mathrm{M}$ & 10 & 12 & Sajidah & $\mathrm{F}$ & 18 & 12 \\
\hline Total & 40 (20 M+20 F) & & 530 & 1084 & $40(20$ M $+20 \mathrm{~F})$ & 525 & 1095 \\
\hline Mean & & -- & 13.25 & $27.1 \%$ & & -- & 13.12 & $27.37 \%$ \\
\hline & & & & & & & & \\
\hline
\end{tabular}

Looked at it from a statistical viewpoint, both groups (experimental and control groups) under investigation fall in the same range with little differences in the decimal marks $(27.1 \%$ vs. $27.37 \%$ ). Such results indicate that the performance of the subjects in the two groups did not differ significantly and that is normal due to that both are given the pre-test which ensure the validity and reliability of the test. Strong correlations were observed between scores in each group (only 11 scores for control group against experimental group made the difference). Depending on the measure, the majority of the subjects in question scored less than the minimum percentage $(50 \%)$.

The scores of all groups (treatment and control groups) fall in the same range (500) (Males treatment and control groups $=525$ and 505 while females treatment and control groups $=559$ and 591). This refers to the fact that the validity of the research is ensured since we are talking about the pre-test. Like any other study's pre-test, the scores remain no more than a base to be compared later with those of the posttest. Again, such outcomes will be clearer if they examined against the posttest's results. Consider: 
Table 2. Performance of the subjects in the post-test: Comparison between the treatment and control groups

\begin{tabular}{|c|c|c|c|c|c|c|c|c|}
\hline \multirow[b]{2}{*}{ No } & \multicolumn{4}{|c|}{ Treatment/ Experimental group } & \multicolumn{4}{|c|}{ Control group } \\
\hline & Subject Name & 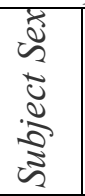 & 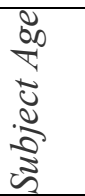 & 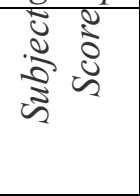 & Subject Name & 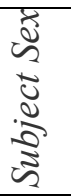 & 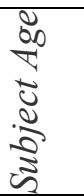 & 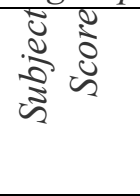 \\
\hline 1 & Saleh & $\mathrm{M}$ & 18 & 89 & Nada & $\mathrm{F}$ & 15 & 23 \\
\hline 2 & Majed & $\mathrm{M}$ & 12 & 67 & Hajar & $\mathrm{F}$ & 14 & 17 \\
\hline 3 & Saqr & $\mathrm{M}$ & 14 & 54 & Hamas & $\mathrm{F}$ & 8 & 11 \\
\hline 4 & Ali & $\mathrm{M}$ & 8 & 47 & Rashad & M & 12 & 33 \\
\hline 5 & Amatallateef & $\mathrm{F}$ & 12 & 85 & Omar & $\mathrm{M}$ & 9 & 16 \\
\hline 6 & Amatala'leem & $\mathrm{F}$ & 9 & 89 & Ashraf & M & 16 & 13 \\
\hline 7 & Badr & $\mathrm{M}$ & 13 & 90 & Mohammad & $M$ & 11 & 24 \\
\hline 8 & Tareq & $\mathrm{M}$ & 14 & 95 & Montaha & $\mathrm{F}$ & 14 & 16 \\
\hline 9 & Parees & $\mathrm{F}$ & 15 & 57 & Ayman & M & 13 & 46 \\
\hline 10 & Bayrout & $\mathrm{F}$ & 9 & 68 & Aayah & $\mathrm{F}$ & 10 & 31 \\
\hline 11 & Tammaah & M & 9 & 94 & Adham & $\mathrm{M}$ & 10 & 37 \\
\hline 12 & Taher & $\mathrm{M}$ & 17 & 58 & Nasser & $\mathrm{M}$ & 11 & 37 \\
\hline 13 & Baraah & $\mathrm{F}$ & 16 & 90 & Haylah & $\mathrm{F}$ & 17 & 27 \\
\hline 14 & Abrar & $\mathrm{F}$ & 11 & 67 & Tawfeeq & M & 13 & 25 \\
\hline 15 & Ahmad & $\mathrm{M}$ & 13 & 69 & Nour & $\mathrm{F}$ & 12 & 29 \\
\hline 16 & Fatimah & $\mathrm{F}$ & 16 & 49 & Najeebah & $\mathrm{F}$ & 18 & 16 \\
\hline 17 & Amatillah & $\mathrm{F}$ & 18 & 60 & Radha'a & $\mathrm{F}$ & 16 & 14 \\
\hline 18 & Abdullateef & M & 8 & 68 & Wafa'a & $\mathrm{F}$ & 15 & 9 \\
\hline 19 & Amriyah & $\mathrm{F}$ & 12 & 74 & Wajedah & $\mathrm{F}$ & 15 & 16 \\
\hline 20 & Abduljaleel & $\mathrm{M}$ & 12 & 59 & Sultan & M & 9 & 38 \\
\hline 21 & Kareemah & $\mathrm{F}$ & 11 & 89 & A'simah & $\mathrm{F}$ & 12 & 46 \\
\hline 22 & Nadiyah & $\mathrm{F}$ & 11 & 67 & Adalah & $\mathrm{F}$ & 11 & 37 \\
\hline 23 & Sariyah & $\mathrm{F}$ & 13 & 98 & Abulwali & $\mathrm{M}$ & 8 & 27 \\
\hline 24 & Sarah & $\mathrm{F}$ & 13 & 45 & A'amal & $\mathrm{F}$ & 8 & 29 \\
\hline 25 & Huda & $\mathrm{F}$ & 18 & 67 & Salah & M & 12 & 18 \\
\hline 26 & Sulayman & $\mathrm{M}$ & 15 & 89 & Ammar & $\mathrm{M}$ & 13 & 27 \\
\hline 27 & Amjad & M & 14 & 90 & Luluah & $\mathrm{F}$ & 18 & 9 \\
\hline 28 & Abdullah & M & 11 & 87 & Bilal & M & 14 & 18 \\
\hline 29 & Abdulmajeed & $\mathrm{M}$ & 16 & 67 & Ziad & M & 12 & 12 \\
\hline 30 & Raghad & $\mathrm{F}$ & 15 & 89 & Ruqayah & $\mathrm{F}$ & 18 & 26 \\
\hline 31 & Hafsah & $\mathrm{F}$ & 14 & 85 & Asma'a & $\mathrm{F}$ & 15 & 39 \\
\hline 32 & Abdurrahman & $\mathrm{M}$ & 14 & 46 & Sumayah & $\mathrm{F}$ & 17 & 28 \\
\hline 33 & Akram & $\mathrm{M}$ & 14 & 79 & Kawthar & $\mathrm{F}$ & 13 & 43 \\
\hline 34 & Taqwa & $\mathrm{F}$ & 13 & 95 & Khawlah & $\mathrm{F}$ & 14 & 34 \\
\hline 35 & Salma & $\mathrm{F}$ & 12 & 68 & Tasneem & $\mathrm{F}$ & 18 & 38 \\
\hline
\end{tabular}




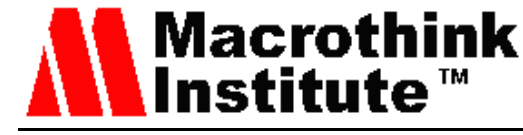

Journal for the Study of English Linguistics

ISSN 2329-7034

2013, Vol. 1, No. 2

\begin{tabular}{|r|r|r|r|r|r|r|r|r|}
\hline 36 & Hadiyah & $\mathrm{F}$ & 18 & 87 & Amal & $\mathrm{F}$ & 10 & 39 \\
\hline 37 & Sayda & $\mathrm{F}$ & 18 & 65 & Sami & $\mathrm{M}$ & 10 & 28 \\
\hline 38 & Abdulkareem & $\mathrm{M}$ & 16 & 77 & Haneen & $\mathrm{F}$ & 10 & 16 \\
\hline 39 & Sadeq & $\mathrm{M}$ & 8 & 97 & Ayham & $\mathrm{M}$ & 16 & 32 \\
\hline 40 & Motaz & $\mathrm{M}$ & 10 & 47 & Sajidah & $\mathrm{F}$ & 18 & 34 \\
\hline Total & $40(20 \mathrm{M}+20 \mathrm{~F})$ & & 530 & 2963 & $40(20 \mathrm{M}+20 \mathrm{~F})$ & 525 & 1021 \\
\hline Mean & & -- & 13.25 & $74.07 \%$ & & -- & 13.12 & $25.52 \%$ \\
\hline
\end{tabular}

Positive results have been reported with Table 1 in both treatment and control groups before using the treatment tool (audio-visual aids and CALI to promote subjects' functional speaking ability. This posttest sought to determine the effects of introducing the tool of treatment on the experimental group throughout the period of the experiment (4 months). A significant change was observed for the treatment group's adjusted total score $(74.07 \%)$ in comparison to the subjects' performance in the pre-test $(27.1 \%)$, and this significant difference was also found between the performance of the subjects of the treatment group and the those of the control group in both tests (pre-and-posttests) for adjusted total score $(74.07 \%$ vs. $27.37 \%$ and $25.52 \%$ ) favoring the experimental group. From a statistical point of view, the control group showed a significant change in their responsive scores in the posttest worse than their performance in the pre-test $(25.52 \%, 27.37 \%$, respectively). Such deterioration in the performance level may be accounted for because of the fact that the students are boring with the ordinary educative aids where there is no interaction to motivate them.

Compared with males, the females' performance level is better (1494 vs. 1469). The researcher believes that it is the influence of the sex where the teacher is a female person and this might affect the overall understanding of the subjects under investigation. In fact, even at the level of the control groups, the control group of the females scored higher (590 vs. 431). Such scores of the control group are not of special importance simple because these are no more than control groups as the name implies.

\section{Conclusions \& Recommendations}

Aids to language teaching are of three broad categories: Conventional aids, technological aids (machines other than computer) and CALL. There are some techniques that can be effectively used for teaching language in general. These strategies can be used for teaching nearly all language aspects including the sound system, grammatical structures and vocabulary (language components) as well as teaching the four language skills and culture. Generally, educative aids are of three types. The first type includes visual aids: (e.g., realia, models, pictures/ drawings, posters, maps (geographic and city plans), boards, cards (flash cards, reading cards- Questions \& Answers), graphs, forms, menus, slides (35 mm and OHP), film strips, silent films, comic books and strips, facial diagrams, clock faces and hands, calendars, charts, letters of the alphabet and numbers, cross-word puzzles, etc.). The second type is related to audio aids (including lab) (e.g., audio cassette/ tape (reel) recorders, radio, phonograph records (record albums), CDs, conventional labs. The third type is that of audio-visual aids (e.g., video tapes, TV, DVD, sound films, synchronized audio recording with visual presentations (slides), action aids (e.g., dramatization, field trips, games, 
pantomime, etc. ) and multimedia (e.g., CALT/ L), the use of internet, interactive or not, etc.).

A very legitimate question here is: What is the importance of educative aids (Audio-visual aids and CALI) in speech language pathology? To answer such question, SLTs need to know the characteristics and benefits of audio-visual aids and CALI. Some of these features are relating to attracting attention, maintaining attention. Some SLTs emphasize that audio- visual aids and CALI can be used in matters relating to the clarification of concepts/ meanings of words and utterances. According to these SLTs, these educative aids participate in increasing the chances of remembrance by increasing means of association, saving time, simulation of language use, and presenting authentic language and natural settings for language use. Others add that audio-visual aids and CALI can be exploited to compensate for lack of experience of teachers, individualize learning and instruction, involve of learners, give variety to the lesson, and provide instant feedback.

Computers in general and computer programs in particular were found to be successful in achieving transfer of trained language abilities in speed of processing to similar untrained tasks. They can be used as means of presentation of text and also as means of presentation of exercises and feedback (and/or evaluation). Moreover, one can implement them for other educational purposes where they can be effectively used as sources of texts and also as a means of providing a record of students' progress. In addition, computers are the best educative environments where one can easily find all types of electronic dictionaries (e.g., Thesauri, Sakhr, Atlas, Longman, Contemporary, Webster, etc.). Other available electronic references include grammatical/ usage information, information sources (encyclopedia, etc.), and internet access where communication takes place with others. Strictly, internet facilities found to be useful for teaching, references, consultation, interaction with others, practicing through chatting, learning individually or through collaboration (on assignments, etc.).

CALI requires some procedures to be undertaken before therapeutic sessions take place. Standing alone is the first procedure and this refers to two important points: Considering class complementary work, and language course (autonomous learning). Network is another procedure that SLTs should pay attention to. They should make sure that all necessary networks (e.g., local network), internet access, supplementary materials, language course (Autonomous learning), etc., are available. Nor must we forget to add also the feature of benefiting from computer mediated communications (CMC) (e.g., e-mail, chat, distant learning(, information tools ( different topics, language aids like dictionaries, and/ or using computer as a tool (word processing, spell checkers, grammar checker, word count).

Programmed instruction (self-teaching/ learning) can be used to break learning task/ information into small bits, present these in frames which require response by the learner and then provide feedback by the system. In fact, a connection ought to be made between the uses of programmed instruction and CALI since the former is a part of the latter. Such uses of the programmed instruction require us to mention something about the advantages of CALI. These include: Individualization, instant feedback, combining efforts of different experts, assessment, follow-up learner's progress, providing diagnostic report on learners, provision of authentic materials, use of multimedia, combination of different resources (lexical, 
grammatical, cultural...) and use of corpus linguistic facilities (such as concordancers- key word in context (KWIC)).

Psychoneurolinguistically speaking, human language can be analyzed into sounds (phonemes), words and/ or sentences. These sounds and sentences can be classified into segmental and supra-segmental phonemes and paragraphs. Instant testing/ evaluation of learners' performances are needed here as this gives us instant feedback. Two basic types should not be neglected here that are the linear programming (move on a single track $(1,2$, $3 \ldots)$, and branched/ branching programming: move in different directions, based on performance (e.g., Answer A leads to frame 4, Answer B leads to frame 10, Answer C leads to frame 1 , and so forth)

In order to recommend the suitable audio-visual aids and CALI for teaching speaking skill including teaching pronunciation / sound system, SLPTs should consider the appropriateness of using the aids, especially when it comes to issues relating sounds' representation. The following guidelines ought to be taken into consideration:

- Conventional spelling/ letters OR phonetic transcription. SLT is strongly recommended to download symbols from the internet.

- Pictures and drawings and realia are also recommended to show the meanings of contrasting words.

- Sounds should be presented (audio presentation).

- Facial diagrams are also recommended with or without animation to explain the articulation of sounds.

- SLTs should tackle comparisons and instant feedback on the learner's performance (Speech recognition facility is required for segmental).

- Line drawings are necessary to indicate intonation patterns and the same thing applies to fonts, colors, and other means to show place of stress (stressed syllables).

Speaking be it monologue (a person speaking to himself) or conversation (two speakers or more) requires using different audio-visual aids and CALI. Visual aids that can be used for teaching writing skill to students of special needs are a lot. Some of them are pictures of different types, maps, graphs, drawings, etc. Hearing a dialogue, memorizing it, and practicing it is an effective means of audio aids that can be used for the same purpose (teaching writing skill to students of special needs). For audio-video aids, computer (speaking software/ simulations for interaction, internet for oral communication or chats, video conferencing) is the best means recommended for students of special needs.

Some requirements that should be considered when teaching speaking skill to students of special needs are necessary. For example, SLT should pay a great attention to the production of sound system. He/she should consider the ways grammatical structures are used in the sentence. Using of vocabulary is another important issue that SLTs should consider. Last but not least is the use of paralinguistic features (such as gestures) that should be taken into 
account. Nor must we forget the application of rules of interaction (initiating conversation, role change, closing, etc.) as an important factor for understanding the way spoken course should be given.

The audio-visual aids and CALI that should be used for teaching spoken to the students of special needs are a lot. These educational aids can be used for teaching spoken in general and oral production of language components in particular. These include: Pictures of different types, maps, graphs, drawings, audio text, written text, interview based on forms (e.g., application forms), combinations tables, word cards, dictionaries, broadcast materials (radio or TV), role play, other video aids, computer (speaking software/ simulations for interaction, internet for oral communication or chats...), games, etc.

Using tape recorders and labs are also of special importance in teaching of spoken. However, there are some purposes for implementing recording materials in teaching spoken to students of special needs. These purposes can be mentioned as follows:

$\checkmark$ Practicing listening comprehension.

$\checkmark \quad$ Practicing pronunciation (segmental and supra-segmental features).

$\checkmark$ Practicing grammatical structures (e.g., pattern drills).

$\checkmark \quad$ Practicing reading.

$\checkmark \quad$ Memorizing dialogues and using them.

$\checkmark$ Teaching dictation.

Furthermore, there are certain rules and procedures that SLTs should draw their attention to. These rules and procedures can be explained as follows:

- Source of the recording should be good (accurate on the phonemic level at least), clearly audible and intelligible, adequate for target learners. (Preferably authentic or by native speaker).

- Instructions should be very clear, preferably coupled with examples.

- Rate of delivery should be adequate (normal).

- Silence blanks for repetition or practice should be suitable. (Usually twice the time used by the master recording or professional person).

- Provision of reinforcement when necessary.

- Making adequate pauses, if needed.

- Making breaks/ pauses at proper points.

- In teaching dialogues, we break the utterance into segments, starting from end of sentence (to maintain proper intonation).

- Segmented utterances and /or text should be delivered as wholes as well at normal rate. 
- Giving full information on content. (Book, lesson, part of lesson, etc.).

- Leave adequate blank at beginning and end of tape.

- Make a full transcript (with full directions, such as indications of pauses, segments to be repeated and other requirements).

The performance of the subjects under investigation was obviously developed when their scores in both pre-and-posttests were compared, whereas the control group showed no change to the best; rather there was a regression (backward) in the levels of performance, suggesting a possible boring subjects felt during the four months of experiment as a result to the routine similarities in the methodology of teaching. Such outcomes are represented in the following figure. Consider:

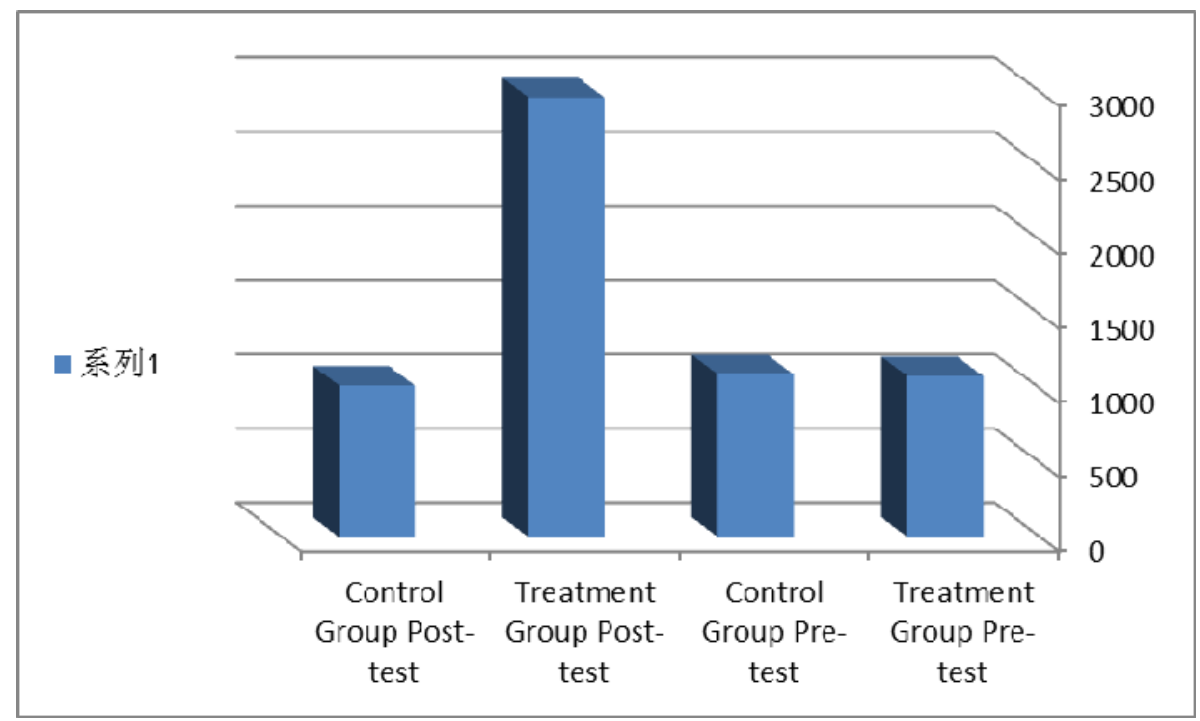

Figure 1. Results of the experimental and control groups' pre-and-posttests: Comparison

These results illustrate not only what pre-and-posttests can or cannot provide; rather, they illustrate the pitfalls and serious effects that may occur if audio-visual aids are not implemented in teaching productive skill like speaking skill for example. Moreover, the results show an effect of using educational aids (audio-visual aids and CALI) in the performance of the students of special needs. This can be clearly observed by comparing the performance of the subjects in the treatment group in both pre-and-posttests in view of their partners in the control group $(27.1 \%, 74.07 \%, 27.37 \%$, and $25.52 \%)$. These findings agree with the outcomes of many other studies conducted on the same subject (Rahimy \& Asaei, 2012; Zumeta, et al., 2012; Iram, 2012; Kirk, et al., 2012; and Mengoni, et al., 2013).

Last but not least, one should not forget the performance the comparative scores of both males and females. In this regard, it can be said that females registered higher scores in comparison to those of males (1494 vs. 1469). Such scores have been pointed out earlier in the explanations of both tables 1 and 2. What concern us are of course the scores of the 
subjects under investigation in posttest (Table 2) where the experiment has already taken place. Figure 2 reveals these findings. Compare:

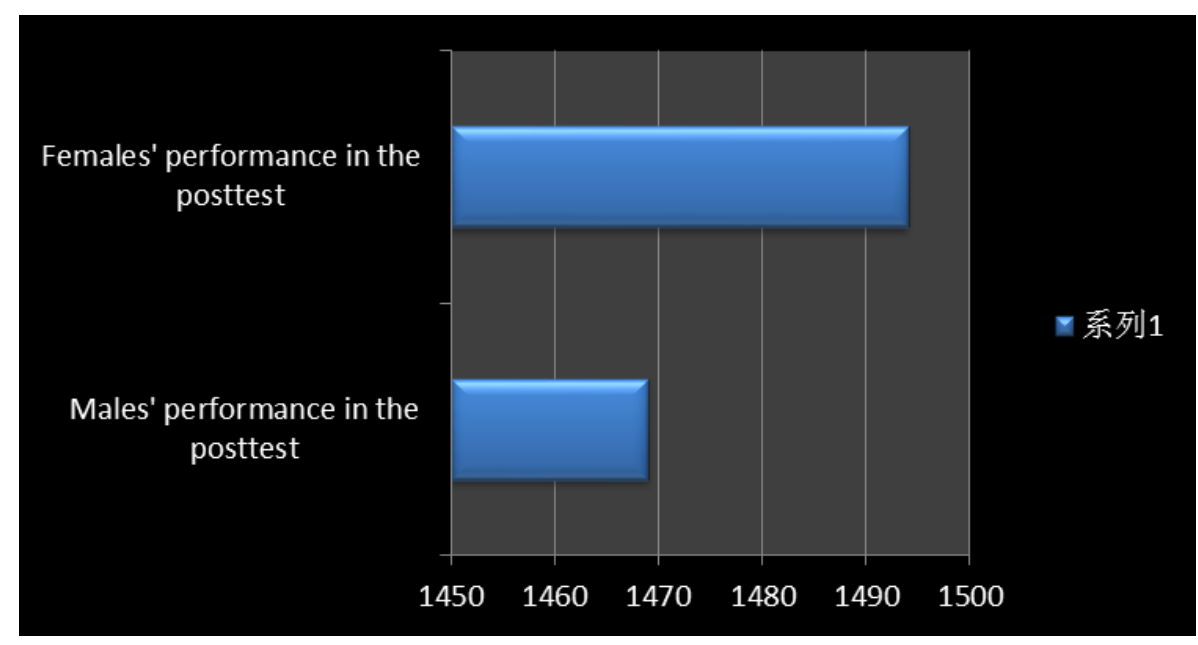

Figure 2. Performance level of males and females: Comparison

\section{Acknowledgement}

I would like to thank Prof. Kebbe who until his last day at King Saud University had kind concern and consideration regarding my academic requirements.

\section{References}

Ahmed, S. S. (2012). Media pedagogy - the medium is the message. Paper presented at the (64), 425-430. Retrieved from http://search.proquest.com/docview/1220675367?accountid=44936.

Álvarez, G. (2012). New technologies in the university context: The use of blogs for developing students' reading and writing skills. RUSC, 9(2), 185-198. Retrieved from http://search.proquest.com/docview/1030155853?accountid=44936.

Anson, C. M., \& Schwegler, R. A. (2012). Tracking the mind's eye: A new technology for researching twenty-first-century writing and reading processes. College Composition and Communication, 64(1), 151-171. Retrieved from http://search.proquest.com/docview/1081830986?accountid=44936.

Block, K., Amie, A., Chery, J., Gina, N., Peggy, A., Deborah, W., \& Sara, H. (1993). "Definitions of Communication Disorders and Variations", Ad Hoc Committee on Service Delivery in the Schools. ASHA, 13-14. http://dx.doi.org/10.1044/policy. RP1993-00208, retrieved 2010-08-07.

Bradham, S. T. (2012). From the ear to the brain: Advances in understanding auditory function, technology and spoken language development. The Volta Review, 112(2), 149-180. Retrieved from http://search.proquest.com/docview/1095617934?accountid=44936. 
Brown, A., Stevens, R., \& Pettifer, S. (2013). Making Graph-Based Diagrams Work in Sound: The Role of Annotation. Human-Computer Interaction, 28(3), 193-221. http://dx.doi.org/10.1080/07370024.2012.697010.

Chen, I., \& Yen, J. (2013). Hypertext annotation: Effects of presentation formats and learner proficiency on reading comprehension and vocabulary learning in foreign languages. Computers \& Education, 63, 416-423. http://dx.doi.org/10.1016/j.compedu.2013.01.005.

Damoiseaux, J., Mallet, K., Vaessen, M., Austen, J., \& Jan-Willem, C. T. (2012). Automatic reading of ANCA-slides: Evaluation of the AKLIDES system. Clinical \& Developmental Immunology, 762874. http://dx.doi.org/10.1155/2012/762874.

Davies, G., \& Higgins, A. (1992). Language and Language Learning. London: CILT.

Devimeenakshi, K., \& Maheswari, C. N. (2012). Using original methods in teaching english language to foreign students (chinese) in indian classroom. English Language Teaching, 5(9), 166-177. Retrieved from http://search.proquest.com/docview/1039540643 ?accountid=44936. http://dx.doi.org/10.5539/elt.v5n9p166.

Diaz-Maurin, F., \& Giampietro, M. (2013). A "Grammar" for assessing the performance of power-supply systems: Comparing nuclear energy to fossil energy. Energy, 49, 162-177.

Fuenzalida, V., \& Sjöberg, U. (2012). The cultural opportunity of children's television public policies in digital Television/A response to "the cultural opportunity of children's TV: Public policies in digital television". Communication Research Trends, 31 (3), 4-22. Retrieved from http://search.proquest.com/docview/1112924145?accountid=44936.

Gessesse, C., \& Sileshi, L. (2013). The Semiotics of HIV/AIDS Bill-Boards and Their Communication Implications: The Case of Bahir Dar and Gondar Towns in Ethiopia. Online Journal Of Communication \& Media Technologies, 3(1), 240-275.

Gilakjani, A. P. (2012). A study on the impact of using multimedia to improve the quality of english language teaching. Journal of Language Teaching and Research, 3(6), 1208-1215. Retrieved from http://search.proquest.com/docview/1272283949?accountid=44936. http://dx.doi.org/10.4304/jltr.3.6.1208-1215.

Gower, L., \& McDowall, J. (2012). Interactive music video games and children's musical development. British Journal of Music Education, 29(1), 91-105. http://dx.doi.org/10.1017/S0265051711000398.

Harcourt, B., \& Templer, B. (2005). "Towards a People's English: Back to BASIC in EIL”. Humanising Language Teaching, 1-5.

Henderson, J. M., \& Luke, S. G. (2012). Oculomotor inhibition of return in normal and mindless reading. Psychonomic Bulletin \& Review, 19(6), 1101-1107. Retrieved from $\mathrm{http}: / /$ search.proquest.com/docview/1268714917?accountid=44936.

http://dx.doi.org/10.3758/s13423-012-0274-2.

Iram, S. (2012). Reading needs, facilities and problems of visually impaired people. Pakistan 
Journal of Library and Information Science, (13), 1-H1. Retrieved from http://search.proquest.com/docview/1242449874?accountid=44936. Available at http://pu.edu.pk/home/journal/8. ISSN 1680-4465.

Ismail, A. S., Hamed, M. A., \& Abdurrahman, G. A. (2012). Employing reading and writing computer-based instruction in english as a second language in elementary schools. International Journal of Business and Social Science,3(12), 3-4. Retrieved from http://search.proquest.com/docview/1022655978?accountid=44936.

Khaliq, M. F., Noorani, M. M., Siddiqui, U. A., \& Anwar, M. (2012). Physicians reading and writing practices: A cross-sectional study from civil hospital, karachi, pakistan. BMC Medical Informatics and Decision Making, 12(1), 76. http://dx.doi.org/10.1186/1472-6947-12-76. http://www.biomedcentral.com/1472-6947/12/76.

Kirk, K. I., Prusick, L., French, B., Gotch, C., Eisenberg, L. S., \& Young, N. (2012). Assessing spoken word recognition in children who are deaf or hard of hearing: A translational approach. Journal of the American Academy of Audiology, 23(6), 464-75. Retrieved from http://search.proquest.com/docview/1022698261 ?accountid=44936. http://dx.doi.org/10.3766/jaaa.23.6.8.

Klingenberg, O. G. (2012). Conceptual understanding of shape and space by braille-reading norwegian students in elementary school. Journal of Visual Impairment \& Blindness, 106(8), 453-465. Retrieved from http://search.proquest.com/docview/1034974451 ?accountid=44936.

Lee, C., Cheung, W., Wong, K., \& Lee, F. (2013). Immediate web-based essay critiquing system feedback and teacher follow-up feedback on young second language learners' writings: an experimental study in a Hong Kong secondary school. Computer Assisted Language Learning, 26(1), 39-60.

Levesque, R. (2007). SPSS Programming and Data Management: A Guide for SPSS and SAS Users, Fourth Edition. SPSS Inc., Chicago Ill. PDF, 1-3. ISBN 1-56827-390-8.

Levy, M. (1997). CALL: context and conceptualisation. Oxford: Oxford University Press.

Macleod, A., Fabiano-Smith, L., Boegner-Pagé, S., \& Sami Fontolliet, S. (2013). Simultaneous bilingual language acquisition: The role of parental input on receptive vocabulary development. Child Language Teaching \& Therapy, 29(1), 131-142. http://dx.doi.org/10.1177/0265659012466862.

Manoli, P., \& Papadopoulou, M. (2012). Graphic organizers as a reading strategy: Research findings and issues. Creative Education, 3(3), 348-356. Retrieved from http://search.proquest.com/docview/1022986447?accountid=44936.

http://dx.doi.org/10.4236/ce.2012.33055.

Mead, A. R., Bradwell, R. P., \& Stokes, G. P. (1999). Advanced atlas of autoantibody patterns. Birmingham: The Binding Site. ISBN 0704485109.

Mengoni, S. E., Nash, H., Hume, C., Bavin, E. L., \& Naigles, L. R. (2013). The benefit of orthographic support for oral vocabulary learning in children with Down syndrome. Journal 
Of Child Language, 40(1), 221-243. http://dx.doi.org/10.1017/S0305000912000396.

Onnis, L., \& Thiessen, E. (2013). Language experience changes subsequent learning. Cognition, 126(2), 268-284. http://dx.doi.org/10.1016/j.cognition.2012.10.008.

Pavan, A., \& Baggio, G. (2013). Linguistic Representations of Motion Do Not Depend on the Visual Motion System. Psychological Science (Sage Publications Inc.), 24(2), 181-188. http://dx.doi.org/10.1177/0956797612450882.

Peek, H. B. (2010). "The Emergence of the Compact Disc". IEEE Communications Magazine 48 (1), 10-17. http://dx.doi.org/10.1109/MCOM.2010.5394021.ISSN 0163-6804.

Peinhardt, R. D., \& Hagler, D. (2012). Peer coaching to support writing development. $\begin{array}{llll}\text { Journal of Nursing } & \text { Education, }\end{array}$ http://dx.doi.org/10.3928/01484834-20121121-02.

Perea, M. (2012). Revisiting huey: On the importance of the upper part of words during reading. Psychonomic Bulletin \& Review, 19(6), 1148-1153. Retrieved from http://search.proquest.com/docview/1268714918?accountid=44936.

http://dx.doi.org/10.3758/s13423-012-0304-0.

Rahimy, R., \& Asaei, S. M. (2012). Audio texts and english speaking ability: Evidence from iranian efl learners. Academic Research International, 3(2), 607-616. Retrieved from http://search.proquest.com/docview/1266226268?accountid=44936.ISSN-L: $\quad 2223-9553$, ISSN: 2223-9944.

Sigrist, R., Rauter, G., Riener, R., \& Wolf, P. (2013). Augmented visual, auditory, haptic, and multimodal feedback in motor learning: A review. Psychonomic Bulletin \& Review, 20(1), 21-53. Retrieved from http://search.proquest.com/docview/1314366722?accountid= 44936 . http://dx.doi.org/10.3758/s13423-012-0333-8.

Swimelar, S. (2013). Visualizing International Relations: Assessing Student Learning Through Film. International Studies Perspectives, 14(1), 14-38. http://dx.doi.org/10.1111/j.1528-3585.2012.00467.x.

Thrasher, A. (1996). "DVD: coming soon to your PC?". Computer Shopper 16 (3), 189.

Wolf, M., Ullman-Shade, C., \& Gottwald, S. (2012). The emerging, evolving reading brain in a digital culture: Implications for new readers, children with reading difficulties, and children without schools. Journal of Cognitive Education and Psychology, 11(3), 230-240. Retrieved from http://search.proquest.com/docview/1124437587?accountid=44936.

Zumeta, R. O., Compton, D. L., \& Fuchs, L. S. (2012). Using word identification fluency to monitor first-grade reading development. Exceptional Children, 78(2), 201-220. Retrieved from http://search.proquest.com/docview/916923335?accountid=44936.

\section{Glossary}

ANCA (Anti-neutrophil cytoplasmic antibodies) = These are a group of autoantibodies and monocytes that are detected as a blood test in a number of autoimmune disorders, but are 
particularly associated with systemic vasculitis. ANCA often "show combinations of both cytoplasmic and perinuclear staining." (Mead, et al., 1999: p.1).

CALL/I/T (Computer-assisted/aided language learning/instruction/teaching) = It is defined as "the search for and study of applications of the computer in language, teaching and learning." (Levy, 1997: p.1). While CALL is related to students, CALT and CALI "fell out of favor among teachers". In that sense, it can be said that while in the former term, the student-centered approach is the dominant perspective, in the latter; a teacher-centered approach is more preferred. CALI/T exhibits all characteristics of English language teaching (ELT) (Davies G. \& Higgins, 1992: p.3).

CD $($ Compact Disc $)=$ It is used for storage of data. It was in March 1974, during a meeting of the audio group, two engineers from the Philips research laboratory recommended the use of a digital format on the $20 \mathrm{~cm}$ optical disc, because an error-correcting code could be added." (Peek, 2010: p. 10).

CMC (Computer-mediated communication $)=$ According to McQuail (2005), CMC is seen as "any communication that occurs through the use of two or more electronic devices." (McQuail, 2005: p.1)

DVD (Digital versatile disc) = It is a digital optical disc storage format. The DVD specification provided a storage capacity of $4.7 \mathrm{~GB}$ for a single-layered, single-sided disc and 8.5 GB for a "dual-layered, single-sided disc." (Thrasher, 1996: p. 16).

ESL/ EFL (English as a second/ foreign language) = It can be defined as the use or study of English by speakers with different native languages in English speaking countries. Unlike ESL, EFl refers to the teaching of English in a non-English-speaking region. Such differences occurred "during the development of English in the 1930s." (Harcourt \& Templer, 2005: p.2).

KWIC (Key word in Context) = It is considered the most common format for concordance lines "especially in the phrase" (Collins English Dictionary, 2003).

OHP (overhead projector) = It is a variant of slide projector that is used to display images to an audience. In the definition of dictionary, "overhead projector is capable of projecting enlarged images of written or pictorial material onto a screen or wall from a transparency placed horizontally below the projector and lighted from underneath"(The American heritage dictionary of the English language, 2009).

SLTs (Speech-Language Therapists) = They are specialized in communication disorders as well as swallowing disorders. They are also called Speech Pathologists (Block et al., 1993, P. 23).

SPSS (Statistical program/package/product/ for social sciences/ and service solution) $=$ It is a software package used for statistical analysis and is among the most widely used programs for statistical analysis in social science. Levesque (2007) listed some statistical operations that are normally undertaken by SPSS software. These include: "Descriptive statistics (Cross tabulation, descriptive frequencies, exploration, etc.), descriptive ratio statistics, bivariate 


\section{Macrothink

statistics (means, t-test, ANOVA, correlation (e.g., bivariate, and partial distances), and nonparametric tests.), and prediction for numerical outcomes (linear regression and prediction for identifying groups (actor analysis, and cluster analysis.)" (Levesque, 2007: p. 392).

\section{Copyright Disclaimer}

Copyright reserved by the author(s).

This article is an open-access article distributed under the terms and conditions of the Creative Commons Attribution license (http://creativecommons.org/licenses/by/3.0/). 